\title{
STUDY ON STRESS AMONG UNDERGRADUATE STUDENTS OF A MEDICAL COLLEGE IN COASTAL ANDHRA PRADESH
}

Sai Shankar Pratap, Anand Acharya, Deepak, Sanjeev Rao

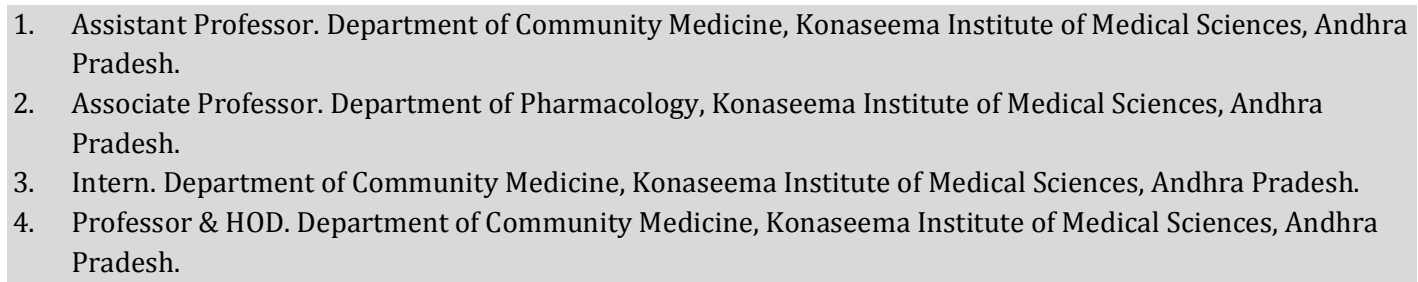

\section{CORRESPONDING AUTHOR:}

Dr. Sai Shankar Pratap,

Konaseema Institute of Medical Sciences,

Amalapuram, E.G. Dist. A.P.533201.

E-mail: prathapss@gmail.com

ABSTRACT: BACKGROUND: Stress is a part of everyone's life. It is normal for everybody to experience stress to some extent, but too much stress may be harmful. Attending college is a rewarding experience but it also can be a time of considerable anxiety and stress for students. Students are subjected to different kinds of experiences which make them vulnerable to undergo a lot of stress. Of late, there is a growing appreciation of stress in medical professionals including medical students, who have very busy and demanding schedule. Sources of stress are classified into two main groups - academic pressures and non-academic sources including financial problems. There are different coping strategies used by students to manage stress. It is important to understand these strategies and encourage the healthy strategies and discourage the others which are potentially harmful. AIM: to determine the sources of stress in undergraduate medical students and the coping strategies used by these students in managing their stress. SETTINGS AND DESIGN: An institutional cross sectional study among undergraduate students of a medical college in coastal Andhra Pradesh. MATERIAL AND METHODS: After the study protocol was given clearance by the Institution Ethics Committee, consent was taken from the undergraduate medical students of Konaseema Institute of Medical Sciences and Research Foundation, Amalapuram, and a predesigned and pretested questionnaire was given which captured information related to basic demographic details followed by questions related to stress and its sources and also the coping strategies used by these students to manage stress. STATISTICAL ANALYSIS: The data collected was entered into Microsoft Excel and analyzed using Epi Info 6 software. Chi Square test was done wherever applicable. RESULTS AND CONCLUSIONS: Total 431 out of 550 medical students (78.4 percent) participated in the study. There were 261 females and 170 males. 'Academic work load', 'long hours of academic work', 'performance in examinations', 'competition for marks' and 'frequency of examinations' were the leading academic sources of stress. 'Quality of food', 'lack of entertainment in the institution', 'worry about future', 'being away from home' and 'lack of time for recreation' were the leading non-academic sources of stress in the students. 'Emotional support from family/friends', 'listening to music/dancing', 'going to place of worship', 'playing sports/games/physical exercises', and 'watching a movie' were reported as the leading coping strategies used by the study subjects. 
KEYWORDS: stress among medical students, academic and non-academic sources of stress, coping strategies

INTRODUCTION: Stress is a part of everyone's life. It is normal for everybody to experience stress to some extent, but too much stress may be harmful. A great deal of research has examined the effects of stress on variables such as adaptational outcomes [1].

Attending college is a rewarding experience but it also can be a time of considerable anxiety and stress for students [2]. Students are subjected to different kinds of experiences which make them vulnerable to undergo a lot of stress such as the pressure of academics with an obligation to succeed, an uncertain future and difficulties of integrating into the system. The social, emotional and physical and family problems, which students face during their college days affects their learning ability and academic performance [3-4]. Too much stress can cause physical and mental health problems, reduce students' self-esteem and may affect students academic achievement [5-6].

Of late, there is a growing appreciation of stress in medical professionals including medical students, who have very busy and demanding schedule [7]. Review of literature suggests that sources of stress are classified into two main groups - academic pressures and non-academic sources including financial problems [8-10].

Apart from its adverse effect on the quality of life of medical students, stress also influences patient care and complex psychodynamics of doctor-patient relationships [11]. As a result of increased stress, medical students can experience an alarming amount of stressassociated anxiety, depression, substance abuse and even suicide. Chronic stress also influences memory and learning, especially problem solving abilities which require flexible thinking. Thus, stress can affect medical decisions and ultimately, patient care [12].

It was reported in the literature that students with an active coping style have lower level of psychological distress [13]. It is therefore important to understand the different coping strategies used by students to manage stress. Some of the coping strategies used by students may be helpful in improving the health in addition to managing stress but there are also some strategies such as smoking or alcoholism which can be the source of some other health problems.

With this background a study was conducted to determine the sources of stress in undergraduate medical students and the coping strategies used by these students.

METHODS: The protocol for carrying out the study was prepared and submitted for clearance of Institutional Ethics Committee of Konaseema Institute of Medical Sciences and Research Foundation, Amalapuram. After getting the clearance, a cross sectional study was carried out among the undergraduate medical students of this medical college in East Godavari district of coastal Andhra Pradesh to understand the perception of stress in undergraduate medical students, explore the sources of stress in them and study the coping strategies used by these students.

The study was planned to be carried out on all the students enrolled in MBBS in this college. An opportunity-type survey was planned and all the students who attended the college on the day of survey were told about the importance of this study and asked to participate. No attempt was made to collect data the students who were absent on the day of survey. A predesigned, pretested questionnaire was distributed among the students studying in different phases of MBBS in this college. A questionnaire was designed to collect information from the 
students and included provision to collect basic demographic details followed by questions related to academic and non-academic sources of stress and the coping strategies. After taking their consent to participate in the study, the questions were explained and the students were asked to answer in the appropriate space provided in the questionnaire. The information provided by the students was entered into Microsoft Excel sheet, rechecked twice by independent persons for any errors, and analyzed using EPI INFO 6 software. Chi Square test was done to study any statistically significant differences in the study group.

RESULTS: There were 550 students studying in different phases of MBBS course in this institution. Out of these, 432 could be contacted and 431 had given consent for participation in the study. Thus, the participation rate was 78.4 percent. The study group comprised of 261 females and 170 males. The mean age of female subjects was 19.54 years with a Standard Deviation of 1.76 whereas the mean age of male subjects was 20.08 years with a Standard Deviation of 1.83. Nineteen female subjects had one or both of the parents working as a doctor, whereas twelve male subjects had one or both of the parents working as a doctor.

Table 1: Academic sources of stress

\begin{tabular}{|l|l|l|l|l|}
\hline Source of stress & $\begin{array}{l}\text { Total students who } \\
\text { experienced stress } \mathrm{n} \\
(\%)\end{array}$ & $\begin{array}{l}\text { Males who } \\
\text { experienced stress } \\
\mathrm{n}(\%)\end{array}$ & $\begin{array}{l}\text { Females who } \\
\text { experienced stress } \\
\mathrm{n}(\%)\end{array}$ & $\begin{array}{l}\mathrm{p} \text { - } \\
\text { value }\end{array}$ \\
\hline $\begin{array}{l}\text { Following the teaching } \\
\text { language }\end{array}$ & $131(30.4)$ & $66(38.8)$ & $65(24.9)$ & 0.002 \\
\hline $\begin{array}{l}\text { Performance in } \\
\text { examinations }\end{array}$ & $203(47.1)$ & $85(50)$ & $118(45.2)$ & 0.33 \\
\hline Competition for marks & $192(44.6)$ & $76(44.7)$ & $116(44.4)$ & 0.957 \\
\hline $\begin{array}{l}\text { Frequency of } \\
\text { examinations }\end{array}$ & $187(43.4)$ & $74(43.5)$ & $113(43.3)$ & 0.962 \\
\hline $\begin{array}{l}\text { Long hours of academic } \\
\text { work }\end{array}$ & $203(47.1)$ & $89(52.4)$ & $114(43.7)$ & 0.778 \\
\hline $\begin{array}{l}\text { Communicating } \\
\text { with/approaching staff }\end{array}$ & $118(27.4)$ & $48(28.2)$ & $70(26.8)$ & 0.747 \\
\hline Academic workload & $238(55.2)$ & $90(52.9)$ & $148(56.7)$ & 0.442 \\
\hline
\end{tabular}

'Academic work load', 'long hours of academic work', 'performance in examinations', 'competition for marks' and 'frequency of examinations' were reported as leading academic sources of stress. A significantly higher proportion of male students reported following the teaching language as a source of stress than female students $(\mathrm{p}<0.005)$. 
Table 2: Non-academic sources of stress

\begin{tabular}{|l|l|l|l|l|}
\hline Source of stress & $\begin{array}{l}\text { Total students } \\
\text { who experienced } \\
\text { stress n (\%) }\end{array}$ & $\begin{array}{l}\text { Males who } \\
\text { experienced } \\
\text { stress n (\%) }\end{array}$ & $\begin{array}{l}\text { Females } \\
\text { who } \\
\text { experienced } \\
\text { stress n (\%) }\end{array}$ & p-value \\
\hline Accommodation & $151(35)$ & $66(38.8)$ & $85(32.6)$ & 0.183 \\
\hline Adjustment with room mates & $93(21.6)$ & $43(25.3)$ & $50(19.2)$ & 0.13 \\
\hline Relation with friends & $99(23)$ & $47(27.7)$ & $52(19.9)$ & 0.062 \\
\hline Feeling of loneliness & $106(24.6)$ & $29(17.1)$ & $77(29.5)$ & 0.003 \\
\hline Lack of entertainment in the institution & $236(54.8)$ & $104(61.2)$ & $132(50.6)$ & 0.03 \\
\hline Lack of time for recreation & $213(49.4)$ & $84(49.4)$ & $129(49.4)$ & 0.998 \\
\hline My health condition & $120(27.8)$ & $48(28.2)$ & $72(27.6)$ & 0.883 \\
\hline Relation with opposite sex & $67(15.6)$ & $39(22.9)$ & $28(10.7)$ & 0.001 \\
\hline Being away from home & $216(50.1)$ & $70(41.2)$ & $146(55.9)$ & 0.003 \\
\hline Financial problem & $103(23.9)$ & $40(23.5)$ & $63(24.1)$ & 0.885 \\
\hline Quality of food & $241(55.9)$ & $98(57.7)$ & $143(54.8)$ & 0.559 \\
\hline High parental expectation & $130(30.2)$ & $59(34.7)$ & $71(27.2)$ & 0.097 \\
\hline Worry about future & $225(52.2)$ & $79(46.5)$ & $146(55.9)$ & 0.055 \\
\hline Sleep disturbances & $136(31.6)$ & $51(30)$ & $85(32.6)$ & 0.575 \\
\hline Political situation of the state/country & $90(20.9)$ & $49(28.8)$ & $41(15.7)$ & 0.001 \\
\hline Family problems & $83(19.3)$ & $32(18.8)$ & $51(19.5)$ & 0.854 \\
\hline
\end{tabular}

'Quality of food', 'lack of entertainment in the institution', 'worry about future', 'being away from home' and 'lack of time for recreation' were reported as leading non-academic sources of stress in the students. A significantly higher proportion of female students reported feeling of loneliness $(p<0.005)$ and being away from home $(p<0.005)$ as sources of stress than male students. A significantly higher proportion of male students reported lack of entertainment in the institution $(\mathrm{p}<0.05)$ and political situation of the state/country $(\mathrm{p}<0.005)$ as sources of stress than female students.

Table 3: Coping strategies used by students to manage stress

\begin{tabular}{|l|l|l|l|l|}
\hline Coping strategy & Total n (\%) & Males n (\%) & Females n (\%) & p-value \\
\hline Acceptance & $267(62)$ & $120(70.6)$ & $147(56.3)$ & 0.003 \\
\hline Emotional support from family/friends & $352(81.7)$ & $137(80.6)$ & $215(82.4)$ & 0.639 \\
\hline Going to place of worship & $324(75.2)$ & $117(68.8)$ & $207(79.3)$ & 0.014 \\
\hline Watching a movie & $294(68.2)$ & $129(75.9)$ & $165(63.2)$ & 0.006 \\
\hline $\begin{array}{l}\text { Playing sports/games/physical } \\
\text { exercises }\end{array}$ & $305(70.8)$ & $133(78.2)$ & $172(65.9)$ & 0.006 \\
\hline Tobacco/alcohol consumption & $39(9.1)$ & $19(11.2)$ & $20(7.7)$ & 0.214 \\
\hline Positive reframing & $324(75.2)$ & $128(75.3)$ & $196(75.1)$ & 0.963 \\
\hline Travelling & $217(50.4)$ & $90(52.9)$ & $127(48.7)$ & 0.385 \\
\hline Meditation & $263(61)$ & $89(52.4)$ & $174(66.7)$ & 0.003 \\
\hline Listening to music/dancing & $349(81)$ & $140(82.4)$ & $209(80.1)$ & 0.556 \\
\hline $\begin{array}{l}\text { Professional support of a } \\
\text { psychologist/counselor }\end{array}$ & $126(29)$ & $56(32.9)$ & $70(26.8)$ & 0.172 \\
\hline
\end{tabular}


'Emotional support from family/friends', 'listening to music/dancing', 'going to place of worship', 'playing sports/games/physical exercises', and 'watching a movie' were reported as the leading coping strategies used by the study subjects. A significantly higher proportion of female students reported 'going to place of worship' $(\mathrm{p}<0.05)$ and 'meditation' $(\mathrm{p}<0.005)$ as coping strategies used by them to manage stress when compared to male students. However, a significantly higher proportion of male students reported 'acceptance' $(\mathrm{p}<0.005)$, 'watching a movie' $(\mathrm{p}<0.05)$ and 'playing sports/games/physical exercise' $(\mathrm{p}<0.05)$ as a coping strategy used by them to manage stress when compared to female students.

DISCUSSION: In the present study, 'academic work load', 'long hours of academic work', 'performance in examinations', 'competition for marks' and 'frequency of examinations' were reported as leading academic sources of stress. Previous studies have also reported that academics/exams are common sources of stress in medical students [14-16].

In the present study, psychosocial factors also played an important role as sources of stress. 'Quality of food', 'lack of entertainment in the institution', 'worry about future', 'being away from home' and 'lack of time for recreation' were reported as leading non-academic sources of stress in the students. Similar findings have been reported in a study from Nepal that has identified 'quality of food in mess', 'high parental expectations', 'lack of entertainment', 'feeling of loneliness and 'worrying about the future' as important psychosocial stressors in medical students [17].

In the present study, the common coping strategies employed by the study subjects were 'emotional support from family/friends', 'listening to music/dancing', 'going to place of worship', 'playing sports/games/physical exercises' and 'watching a movie'. Studies from the United Kingdom have reported, use of alcohol, tobacco and drugs as common coping strategies adopted by the medical students [18-20].

CONCLUSIONS: Stress is a very common experience of undergraduate medical students. This study gives us an understanding of the common academic and non-academic sources of stress in undergraduate medical students and also about the coping strategies used by these students to manage stress. This will help the management of this institution to act upon the modifiable stressors and help the student. There is a need to further analyze the stressors and to address them by the management of the institution by using student advisors, peer counseling and education. There is a need to bring about changes in the academic workload and schedule and in the quality of teaching and evaluation system. There is a need to make the social environment more conducive for the students to minimize their stress by improving their living conditions and recreational facilities. The study has also brought out the common coping strategies to manage stress, as reported by the students. The management of the institution can again use this information to encourage healthy measures and discourage the harmful stress coping strategies mentioned by the students. Some students reported tobacco/alcohol consumption as a coping strategy and this can be harmful to their health, and therefore steps must be taken to encourage them to leave this and shift to other healthy coping strategies. The limitation of the study is that the sources of stress pointed out by the students are self-reported and there is no objective manner of verifying it. Hence, we had to go by whatever the student had reported and there is no method of verifying whether the source of stress mentioned by the study subject was really a stressor for him or not. 
ACKNOWLEDGEMENTS: The authors express their heartfelt thanks to Dr. Vishwanath, Dr. B. Praveen, and Dr. Ch. Kiransri for their assistance in data collection. The authors also express a special thanks to all the students who participated in study.

\section{REFERENCES:}

1. Lazarus R, DeLongis A, Folkman S \&Gruen R (1985). Stress and adaptational outcomes. American Psychologist; 40(7): 770-779

2. Dyson, R., \& Renk, K. (2006). Freshmen adaptation to university life: Depressive symptoms, stress, and coping. Journal of Clinical Psychology, 62, 1231-1244.

3. Fish C, Nies MA: Health promotion needs of students in a college environment. Public Health Nurs 1996, 13:104-11.

4. Chew-Graham CA, Rogers A, Yassin N: 'I wouldn't want it on my CV or their records': medical students' experiences of help seeking for mental health problems. Med Educ 2003, 37:873-80.

5. Silver HK, Glicken AD: Medical student abuse. Incidence, severity, and significance. JAMA 1990, 263:527-32.

6. Niemi PM, Vainiomaki PT: Medical students' academic distress, coping and achievement strategies during the pre-clinical years. Teach Learn Med 1999, 11:125-34.

7. Shah C, Trivedi RS. Coping of Stress by Medical Students. J Clin Diag Res 2009 19; 401523

8. Vitaliano PP, Russo J, Carr JE, Heerwagen JH: Medical school pressures and their relationship to anxiety. J Nerv Ment Dis 1984, 172:730-6.

9. Guthrie EA, Black D, Shaw CM, Hamilton J, Creed FH, Tomenson B: Embarking upon a medical career: psychological morbidity in first year medical students. Med Educ 1995, 29:337-41.

10. Firth J: Levels and sources of stress in medical students. BMJ 1986, 292:1177-80.

11. Troyer D, Ullrich IH, Yeater RA, Hopewell R. Physical activity and condition, dietary habits, and serum lipids in second year medical students. J Am Coll Nutr 1990 ; (4):30307

12. Sugira G, Shinada K, Kawaguchi Y. Psychological well being and perceptions of stress amongst Japanese dental students. Eur J Dent Educ 2005 ; 9(1):17-25

13. Redhwan, A., A.Ra Sami, AJa Karim, Rb Chan and MIc Zaleha, 2009. Stress and coping strategies among management and science university students: A qualitative study. Int. Med. J., 8(2): 11-15.

14. Shaikh BT, Kahloon A, Kazmi M, Khalid H, Nawaz K, Khan N, Khan S: Students, stress and coping strategies: a case of Pakistani medical school. Educ Health (Abingdon) 2004, 17:346-53.

15. Stewart SM, Betson C, Marshall I, Wong CM, Lee PWH, Lam TH: Stress and vulnerability in medical students. Med Educ 1995, 29:119-27.

16. Sherina MS, Rampal L, Kaneson N: Psychological stress among undergraduate medical students. Med J Malaysia 2004, 59:207-11

17. Chandrashekhar T Sreeramareddy, Pathiyil R Shankar, VS Binu, Chiranjoy Mukhopadhyay, Biswabina Ray and Ritesh G Menezes. Psychological morbidity, sources of stress and coping strategies among undergraduate medical students of Nepal. BMC Medical Education 2007, 7:26. 
18. Guthrie E, Black D, Bagalkote H, Shaw C, Campbell M, Creed F: Psychological stress and burnout in medical students: a 5-year prospective longitudinal study. J Roy Soc Med 1998, 91(5):237-243.

19. Miller P, Surtees PG: Psychological symptoms and their course in first year medical students as assessed by the Interval General Health Questionnaire (I-GHQ). Br J Psychiatry 1991, 159:199-207.

20. Ashton CH, Kamali F: Personality, lifestyles, alcohol and drug consumption in a sample of British medical students. Med Educ 1995, 29:187-92. 